\title{
Differential pulse stripping voltammetric determination of paracetamol in pharmaceutical tablet samples using murexide modified carbon paste electrode
}

\author{
${\text { Yonas Beyene } \text { Yohannes }^{1 *} \text { and Mohammed Hajole Erba }}^{1}$ \\ ${ }^{1}$ Department of Chemistry, Bahir Dar University, 79, Bahir Dar, Ethiopia
}

\begin{abstract}
As an acetyl aniline drug, paracetamol (PA) has antipyretic and analgesic functions, which is suitable for the remedy of fever, headache and joint ache. The murexide modified carbon paste electrode was characterized by cyclic voltammetry and electrochemical impedance spectroscopy and compared with bare carbon paste electrode. In this study, murexide-carbon paste electrode (MXCPE) was described for the differential pulse stripping voltammetric determination of paracetamol in pharmaceutical tablet sample. The MXCPE exhibited a better electrocatalytical behavior for the oxidation of PA as evidenced by nearly two folds of current enhancement and a shift of the onset potential by $65 \mathrm{mV}$ in comparison with a bare carbon paste electrode. Differential pulse stripping voltammetry peak currents of PA increased linearly with their concentrations in the ranges of $5-1000 \mu \mathrm{M}$ with a detection limit of $0.09 \mu \mathrm{M}(\mathrm{S} / \mathrm{N}=3)$. The determination of the analyte in pharmaceutical samples was found in the range $97.6-106.0 \%$ of the theoretical values and a recovery result between 94.6 and $96.8 \%$ was obtained. For selective determination of PA in the presence of AA was successfully performed.
\end{abstract}

Keywords: Electrochemical oxidation; Murexide; Paracetamol; Voltammetric determination DOI: https://dx.doi.org/10.4314/ejst.v14i3.1

\section{INTRODUCTION}

As a pain-relieving for home medication for over 50 years, paracetamol (PA) is putative as an effective drug for the respite of pain and fever in adults and children. Paracetamol (N-acetyl-p-aminophenol) (Scheme 1) has been used extensively for the respite of ache associated with a backache, headache, arthritis and post-surgical pain (Anderson, 2008). Hence, PA resides in a sole situation among analgesic drugs (Bertolini et al., 2006). Although PA is regarded as an excellent profile safe medicine taken in a recommended dose, the large-scale therapeutic use of this drug needs the development of simple, sensitive, selective and accurate analytical method for its determination.

\section{*Corresponding author: yonasb94@gmail.com}

(C) This is an Open Access article distributed under the terms of the Creative Commons Attribution License (http://creativecommons.org/licenses/CC BY4.0) 


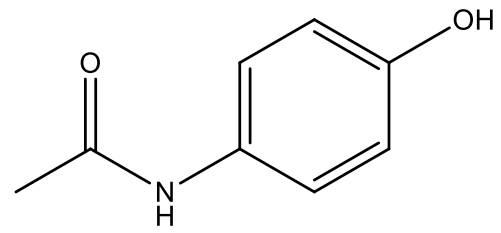

Scheme 1. Structure of paracetamol

Numerous analytical techniques including fluorescence (Moreira et al., 2005), high performance liquid chromatography (Shinde et al., 1995; Goyal and Jain, 2007), spectrophotometry (Baptistao et al., 2011), capillary electrophoresis hyphenated to mass spectrometry (Lecoeur et al., 2019), and FTIR and Raman spectrometry (AlZoubi et al., 2002) are among the techniques used for the determination of PA in real samples. The aforementioned methods are expensive, time consuming and involve tedious sample pre-treatment procedure, and they are less sensitive and selective making them inappropriate for monotonous analysis (Li et al., 2018). In the past decades, electrochemical methods of analysis have been reported for the determination of PA (Shahmiri et al., 2013; Zhu et al., 2014; Görçay et al., 2016; Foroughi et al., 2019; Meenakshi et al., 2020). Though for the determination of PA many available electrochemical techniques are used, the use of murexide (MX) as a modifier has not been reported.

Murexide (ammonium purpurate) is the ammonium salt of purpuric acid (Scheme 2 ), which is used in analytical chemistry as indicator for complexometric titrations of $\mathrm{Ca}, \mathrm{Cu}, \mathrm{Ni}, \mathrm{Co}$, Th and rare earth metal ions (Mohran, 2009). Anil Kumar et al. (2019) reported electrochemical sensor application of electrodeposited conductive poly(murexide) film on the surface of glassy carbon electrode.

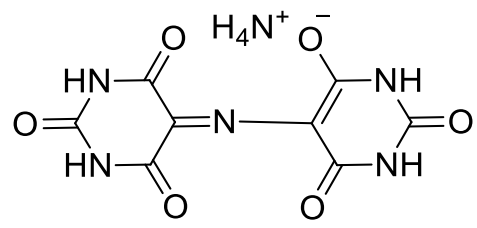

Scheme 2. Structure of murexide (MX)

In this study, we report the application of murexide modified carbon paste electrode (MXCPE) for differential pulse stripping voltammetric determination of paracetamol in pharmaceutical tablet formulation, which to the best of our knowledge is not reported for the same. 


\section{MATERIALS AND METHODS}

\section{Chemicals and reagents}

The chemicals used include paracetamol (99.8\%, Merck), potassium phosphate dibasic $\left(\mathrm{K}_{2} \mathrm{HPO}_{4}\right)(99.0 \%$, Titan Biotech LTD), potassium phosphate monobasic $\left(\mathrm{KH}_{2} \mathrm{PO}_{4}\right)(99.0 \%$, Titan Biotech LTD), sodium hydroxide $(97 \%$, Blulux, India), hydrochloric acid (37\%, LobaChemie Pvt. Ltd.), graphite powder (Blulux Laboratories Ltd.), paraffin oil light (BDH, England), murexide (98.8\%, Merck).

\section{Apparatus and instruments}

All electrochemical experiments were performed with a CHI 760D electrochemical workstation ( $\mathrm{CH}$ Instruments, USA) connected to a personal computer using a conventional three-electrode system; platinum coil as a counter electrode, $\mathrm{Ag} / \mathrm{AgCl}$ $(3 \mathrm{M} \mathrm{KCl})$ as a reference electrode, and an unmodified carbon paste (CPE) or murexide modified carbon paste electrode (MXCPE) as a working electrode. $\mathrm{A} \mathrm{pH}$ meter (AD8000, Romania), and an electronic balance (Nimbus, ADAM) were used to measure the $\mathrm{pH}$ and mass, respectively. All experiments were performed at room temperature, and the electrode potentials quoted are versus $\mathrm{Ag} / \mathrm{AgCl}$ electrode.

\section{Procedure}

\section{Preparation of the working electrode (bare CPE and MXCPE)}

The bare carbon paste electrode (CPE) was prepared by homogeneous mixing of $70 \%$ graphite powder and 30\% paraffin oil (as binding agent) (Shahmiri et al., 2013). The modified murexide carbon paste electrode (MXCPE) was prepared by substituting corresponding amounts of graphite powder $(5,10,15,20$, and $25 \% \mathrm{w} / \mathrm{w}$ ratio of the modifier (MX) relative to the graphite powder) and paraffin oil (30\%) and manually homogenizing the mixture using mortar and pestle. Both the bare and modified active pastes were then left for 24 hours and packed into a cavity of plastic tube $(\mathrm{d}=3 \mathrm{~mm})$ by tapping and using copper wire $(\mathrm{d}=1 \mathrm{~mm})$ to make electric contact. The electrode surface was polished on a clean paper until it had a shiny surface.

\section{Analytical procedures}

For voltammetric experiments, the working electrode (either unmodified CPE or MXCPE) was placed in $0.1 \mathrm{M} \mathrm{pH} \mathrm{7.0} \mathrm{PBS} \mathrm{containing} \mathrm{anticipated} \mathrm{concentration} \mathrm{of}$ PA. CV and DPSV techniques were used for the determination of PA. For CV the measurement was taken in the potential window from -0.2 to $+1.0 \mathrm{~V}$ at a scan rate of $50 \mathrm{mV} \mathrm{s}^{-1}$. DPSV under optimized parameters (accumulation potential of $0.5 \mathrm{~V}$ and accumulation time of $30 \mathrm{~s}$ ) and default parameters (amplitude $25 \mathrm{mV}$, step potential $4 \mathrm{mV}$, sample width $20 \mathrm{~ms}$ and pulse width $25 \mathrm{~ms}$ ) was employed for the quantitative analyses of PA in PA tablet formulations of different brands. 
Electrochemical impedance spectroscopy (EIS) measurements were carried out in the frequency range from $100 \mathrm{kHz}$ to $0.01 \mathrm{~Hz}$. A $0.1 \mathrm{M}$ of phosphate buffer solution (PBS) was prepared from equimolar $(0.1 \mathrm{M})$ stock solution of $\mathrm{K}_{2} \mathrm{HPO}_{4}$ and $\mathrm{KH}_{2} \mathrm{PO}_{4}$ and employed as supporting electrolyte. All solutions were prepared in double distilled water.

\section{Sample preparation}

Commercial pharmaceutical tablet samples (Adol Julphar (Ethiopia), Panadol Adva (Kenya), and Para-Denk (Germany) all labelled $500 \mathrm{mg}$ PA/tablet were inspected for the determination of the content of PA. A stock solution of each brand of tablet with $0.5 \mathrm{mM}$ PA concentration in $\mathrm{pH}$ 7.0 PBS was prepared by dissolving an adequately weighed $0.1 \mathrm{~g}$ powder PA of each brand transferred in to a $250 \mathrm{~mL}$ volumetric flask (Barsan et al., 2015).

\section{RESULTS AND DISCUSSION}

\section{Characterization of MXCPE}

The characterization of MXCPE was performed by cyclic voltammetry (CV) and electrochemical impedance spectroscopy (EIS). Comparative electrocatalytic properties of the electrodes were studied using $\left[\mathrm{Fe}(\mathrm{CN})_{6}\right]^{-3} /\left[\mathrm{Fe}(\mathrm{CN})_{6}\right]^{-4}$ as a probe. The cyclic voltammograms obtained for $5 \mathrm{mM} \mathrm{Fe}(\mathrm{CN})_{6}{ }^{3-4-}$ redox probe using bare $\mathrm{CPE}$ and MXCPE electrodes are presented in Figure 1(A). It is clearly seen that, the current response at MXCPE was largely increased, indicating that the electrochemical active sites of the bare CPE increased by MX surface modification. And the peak potential separation $\left(\triangle \mathrm{E}_{\mathrm{p}}\right)$ at MXCPE and bare CPE was found to be $137 \mathrm{mV}$ and $510 \mathrm{mV}$, respectively. It is perceived that the electron transfer rate increases with a decrease in the value of $\Delta \mathrm{E}_{\mathrm{p}}$ (Bard and Faulkner, 2001). The redox peak current is also higher in the case of MXCPE which is an indicator of increasing surface area of the electrode. In addition the Randles-Sevcik equation (Kissinger and Heineman, 1983) was utilized to measure the effective surface area by:

$$
I_{p}=2.69 \times 10^{5} A D^{1 / 2} n^{3 / 2} v^{2 / 2} \mathrm{C}
$$

where $I_{p}$ refers to the peak current (A), $\mathrm{n}$ is the number of electrons transferred, $\mathrm{A}$ is effective electrode area $\left(\mathrm{cm}^{2}\right), v$ is the scan rate $\left(\mathrm{Vs}^{-1}\right), \mathrm{C}_{0}$ and $\mathrm{D}_{0}$ the molar concentration $\left(\mathrm{molcm}^{-3}\right)$ and diffusion coefficient $\left(\mathrm{cm}^{2} \mathrm{~s}^{-1}\right)$ of $\left[\mathrm{Fe}(\mathrm{CN})_{6}\right]^{4-}$, respectively. Under the measured conditions $\left(\mathrm{T}=298 \mathrm{~K}, \mathrm{v}=50 \mathrm{mVs}^{-1}, \mathrm{C}_{0}=5.0\right.$ $\mathrm{mM}, \mathrm{D}_{0}=7.6 \times 10^{-6} \mathrm{~cm}^{2} \mathrm{~s}^{-1}$ ) (Zheng et al., 2013) the effective surface area was estimated to be $0.012 \mathrm{~cm}^{2}$ and $0.038 \mathrm{~cm}^{2}$ for bare CPE and MXCPE, respectively. As a result, current response for the redox couple $\left[\mathrm{Fe}(\mathrm{CN})_{6}\right]^{3-/ 4-}$ increased with rise in the effective surface area of the murexide modified electrode. To evaluate the electrical conductivity of the electrodes, EIS analysis was performed on the redox probe of $5 \mathrm{mM} \mathrm{Fe}(\mathrm{CN})_{6}^{3-/ 4-}$ as shown in Figure 1(B). The bare CPE has displayed an 
enlargement with an electron transfer resistance while the Nyquist plot of MXCPE shows almost a straight line which suggested its lower electron transfer. Generally, almost a straight line plots at high frequencies imply that the electrode processes are mass transfer-controlled (Ghadimi et al., 2016). These results were in a good agreement with the results obtained with $\mathrm{CV}$ proving the electrocatalytical behavior of MXCPE.
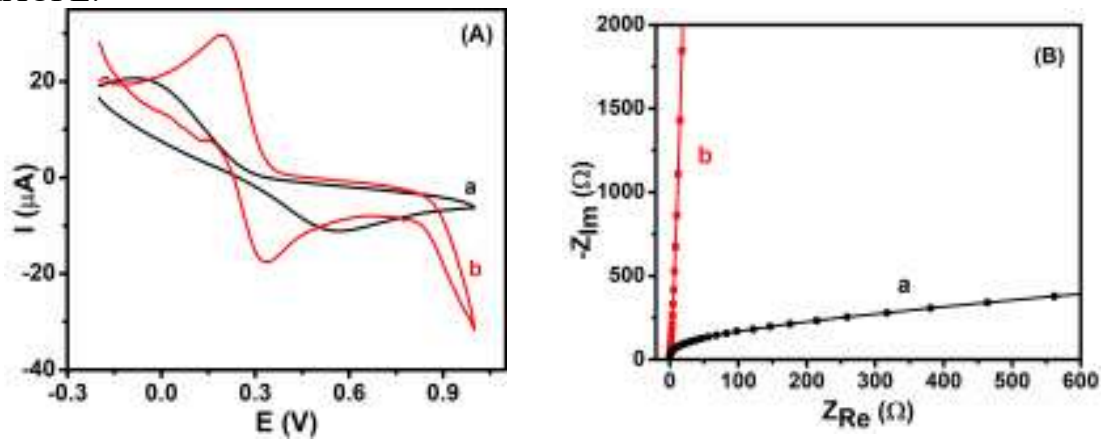

Figure 1. (A) Cyclic voltammograms, and (B) Nyquist diagrams of bare CPE (a) and MXCPE (b) of $5 \mathrm{mM} \mathrm{Fe}(\mathrm{CN}) 6^{3-4-}$ in $0.1 \mathrm{M} \mathrm{KCl}$ redox probe (scan rate for $\mathrm{CV}: 50 \mathrm{mVs}^{-1}$, frequency range for EIS: $10^{-2}$ to $10^{5} \mathrm{~Hz}$ at $0.40 \mathrm{~V}$ ).

\section{Electrochemical Behavior of Paracetamol at MXCPE}

The CVs of the bare CPE and MXCPE recorded in pH 7.0 PBS at scan rate of 50 $\mathrm{mV} \mathrm{s}^{-1}$ in the presence and absence of $0.5 \mathrm{mM}$ PA were shown in Figure 2. As predictable, no anodic or cathodic peaks appeared at either bare CPE or MXCPE in PBS in the absence of PA. However, well-defined oxidation peak was observed for $0.5 \mathrm{mM}$ PA in $\mathrm{pH} 7.0 \mathrm{PBS}$ around $0.68 \mathrm{~V}$ and $0.60 \mathrm{~V}$ at bare CPE and MXCPE, respectively while no peak was observed in the reverse scan direction suggesting that PA undergoes oxidation irreversibly at both electrodes (Figure 2), which agrees with previous reports (Khaskheli et al., 2013; Bharathi et al., 2018).

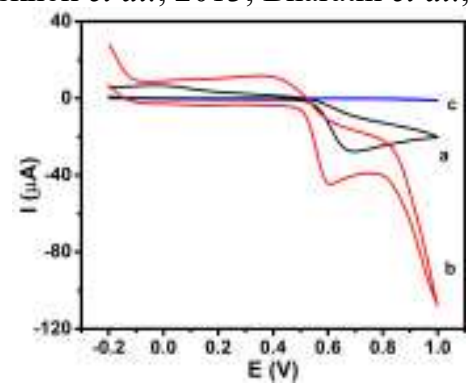

Figure 2. Cyclic voltammograms of a) bare CPE, b) MXCPE, and c) MXCPE in $\mathrm{pH}$ 7.0 PBS containing ( $a$ and b) $0.5 \mathrm{mM} \mathrm{PA}$ and no PA (c) at scan rate of $50 \mathrm{mV} \mathrm{s}^{-1}$. 
In contrast to the bare $\mathrm{CPE}$, an oxidation peak with enhanced current at the MXCPE (Figure 2, curve b) with an onset potential of $65 \mathrm{mV}$ to more negative region confirmed the electrocatalytic ability of the MXCPE towards PA.

\section{Effect of murexide/graphite ratio on peak current of PA}

The effects of the proportion of MX in the carbon paste on cyclic voltammetric responses of the modified electrode for $0.5 \mathrm{mM}$ PA in $\mathrm{pH}$ 7.0 PBS was examined by varying the amount of murexide (MX) from 5 to $25 \%$. As can be seen from the Inset of Figure 3, the oxidative current response of the modified electrode for PA increased with the amount of MX up to $15 \%$ and then decreased dramatically at MX amount above $15 \%$. Hence, $15 \%$ of MX modified CPE was chosen as the optimum for the study of all other parameters.

\section{Potential scan rate effect}

The effect of scan rate on the oxidation peak potential $\left(\mathrm{E}_{\mathrm{pa}}\right)$ and peak current $\left(\mathrm{I}_{\mathrm{pa}}\right)$ of PA at MXCPE was examined in the scan rate range $10-200 \mathrm{mV} \mathrm{s}^{-1}$. As depicted in Figure 4(A), the peak potential shift in the positive direction observed with increasing scan rate for $0.5 \mathrm{mM} \mathrm{PA}$ in $\mathrm{pH} 7.0 \mathrm{PBS}$ solution further confirmed the irreversibility of the oxidation of PA at the MXCPE. As can be inferred from the inset of Figure 4(A), there is a linear relationship between $\log I_{p a}$ and $\log v$, with a slope of 0.39 . The obtained slope value acquired for PA is close to the theoretical value $(0.50)$ predictable for electrochemical process controlled by diffusion which received a good support from the literature (Meenakshi et al., 2020).

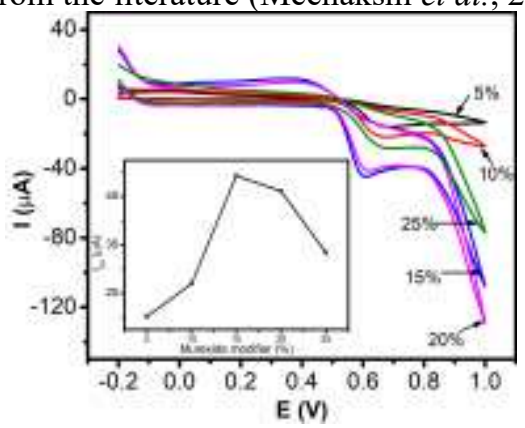

Figure 3. CVs $0.5 \mathrm{mM}$ PA in $\mathrm{pH} 7.0 \mathrm{PBS}$ at CPE modified with MX of various amounts (5-25\%). Inset: the plot of anodic peak current of PA versus amount of MX added as modifier. 


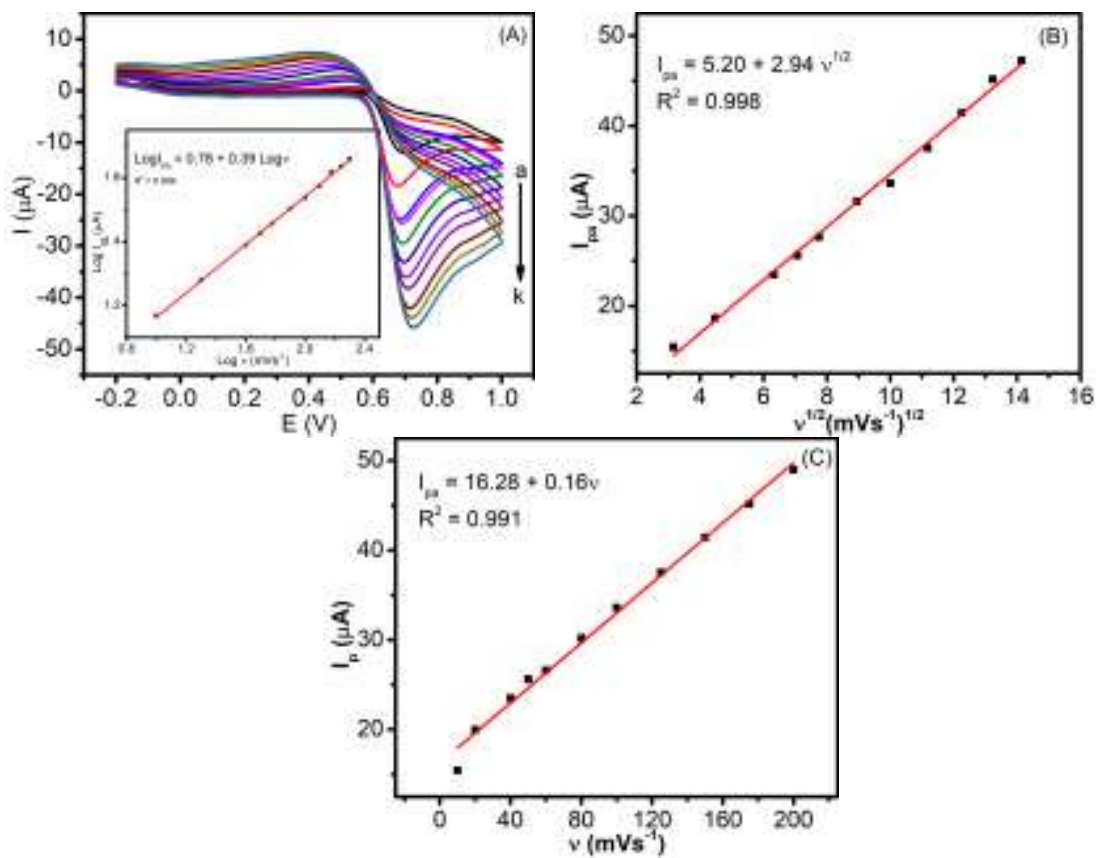

Figure 4. (A) Cyclic voltammograms of MXCPE in PBS pH 7.0 containing $0.5 \mathrm{mM}$ $\mathrm{PA}$ at various scan rates (a-k: 10, 20, 40, 50, 60, 80, 100, 125, 150, 175, and 200 $\mathrm{mV} \mathrm{s}^{-1}$, respectively), (B) plot of oxidative peak current versus square root of scan rate, and (C) plot of oxidative peak current versus scan rate. Inset: plot of log of oxidative peak current versus log of scan rate.

Further evidence for non-adsorptive behavior of PA was obtained as shown in Figure 4(B), the peak current of PA showed linear dependence on the square root of scan rate with the regression equation of $\mathrm{I}_{\mathrm{pa}}(\mu \mathrm{A})=5.20+2.94 \mathrm{v}^{1 / 2}\left(\mathrm{R}^{2}=0.998\right)$ in comparison to the plot of oxidative peak current versus scan rate (Figure $4(\mathrm{C})$ ) with regression equation of $\mathrm{I}_{\mathrm{pa}}(\mu \mathrm{A})=16.28+0.16 \mathrm{v}\left(\mathrm{R}^{2}=0.991\right)$. With increasing scan rate (Figure 5), anodic peak potentials shifted to more positive values (Filik et al., 2014). Figure 5 shows the relationship between $E_{p a}(V)$ and $\ln (v)$ for scan rates of 10 to $200 \mathrm{mVs}^{-1}$ produces a linear regression equation of $\mathrm{E}_{\mathrm{pa}}=0.023 \ln (\mathrm{v})+0.59$ $\left(\mathrm{R}^{2}=0.999\right)$. Based on the Laviron theory (Laviron, 1979), the slope of the line is equal to $R T / \alpha n F$. Hence the charge transfer coefficient $(\alpha)$ and the electron transfer number (n) are calculated to be 0.55 and 2.05, respectively. Incorporating the value of $\alpha$ in Eq. (2), the standard heterogeneous reaction rate constant; $K_{s}\left(s^{-1}\right)$ is predicted to be $2.24 \mathrm{~s}^{-1}$. On the surface of MXCPE the adsorbed amount of PA was further calculated by the following equation: $I_{p}=n^{2} F^{2} A \Gamma v /_{4 R T}$ (Laviron, 1979). Using the association of $i_{p a}$ with $v$, (slope $\left.=0.17\right)$ the value of the surface 
concentration of PA $(\Gamma) 2.34 \times 10^{-6} \mathrm{~mol} / \mathrm{cm}^{2}$ was obtained. This high surface concentration can be credited to the MX modifier. This behavior has a good support from literature (Bouabi et al., 2016; Meenakshi et al., 2020).

$$
\log K_{s}=\alpha \log (1-\alpha)+(1-\alpha) \log \alpha-\log \left(\frac{R T}{n F V}\right)-\alpha(1-\alpha) \frac{n F E}{2 \cdot 3 R T}
$$

where R, F, T, and $v$ are the usual meaning of universal gas constant $\left(\mathrm{JK}^{-1} \mathrm{~mol}^{-1}\right)$, Faraday constant $\left(\mathrm{Cmol}^{-1}\right)$, absolute temperature $(\mathrm{K})$, and scan rate $\left(\mathrm{mVs}^{-1}\right)$.

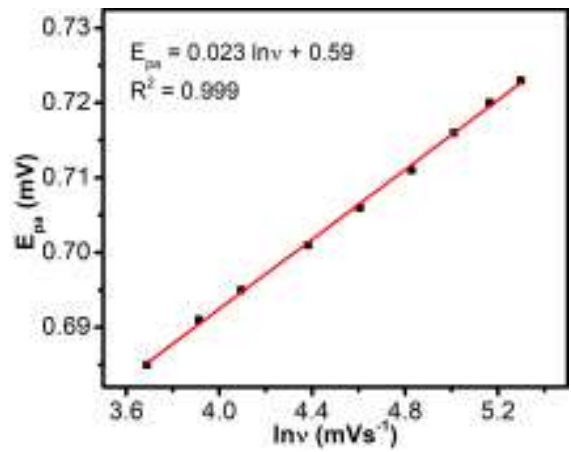

Figure 5. Plot of $\mathrm{E}_{\mathrm{pa}} v s . \ln v$ of $0.5 \mathrm{mM}$ PA in PBS of $\mathrm{pH} 7.0$ on MXCPE.

\section{Influence of pH on PA oxidation}

The effect of $\mathrm{pH}$ on the electrochemical response of PA on the surface of MXCPE in PBS was investigated in the $\mathrm{pH}$ range $4.0-9.0$. Figure 6(A) represents CVs of $0.5 \mathrm{mM} P A$ at MXCPE in different $\mathrm{pH}$ range. The anodic peak potential $\left(\mathrm{E}_{\mathrm{pa}}\right)$ of PA was found to be dependent on $\mathrm{pH}$ and shifted to less positive potential with increasing $\mathrm{pH}$, suggesting the involvement of protons in the oxidation reaction of PA (Figure 6). Similar trends have been reported (Gowda et al., 2015; Chipeture et $a l ., 2019)$. From the plot of $\mathrm{E}_{\mathrm{pa}}$ vs. pH (Figure 6(B)), it is clearly observed that the oxidation peak potential of PA shifted in the negative potential direction with increasing $\mathrm{pH}$. A linear relationship between oxidation peak potential and $\mathrm{pH}$ was observed with a regression equation:

$$
E_{p a}(V)=0.826-0.037 p H \quad\left(R^{2}=0.997\right) .
$$

The slope of the graph should be equal to $-59 \mathrm{mV} \mathrm{p} / \mathrm{n}$ where $\mathrm{p}$ is the number of protons involved in the electrode reaction, $\mathrm{n}$ is the number of electrons transferred and the rest are commonly known constants (Shah et al., 2014). In this study using $\mathrm{MXCPE}$, the $\mathrm{p} / \mathrm{n}$ value for PA is calculated to be 0.61 which infers an unequal number of protons and electros are involved in the oxidation process. Hence for PA, a slope of $-37.4 \mathrm{mV}$ per $\mathrm{pH}$ unit indicates that the electrode process is more complex and the ratio of proton and transferred electrons is predicted to be $1: 2$. Li et al. reported a non-equal number of two electrons and one proton transfer process with a slope value of $-38 \mathrm{mV} / \mathrm{pH}$ ( $\mathrm{Li}$ et al., 2018). The possible oxidation mechanism of paracetamol on the surface of MXCPE was illustrated in Scheme 3. 
The anodic oxidation peak currents decreased and increased with an increase in $\mathrm{pH}$ from 4.0 and then maximum was reached at 7.0 (Figure 6(B)) and $\mathrm{pH} 7.0$ was opted for further studies.
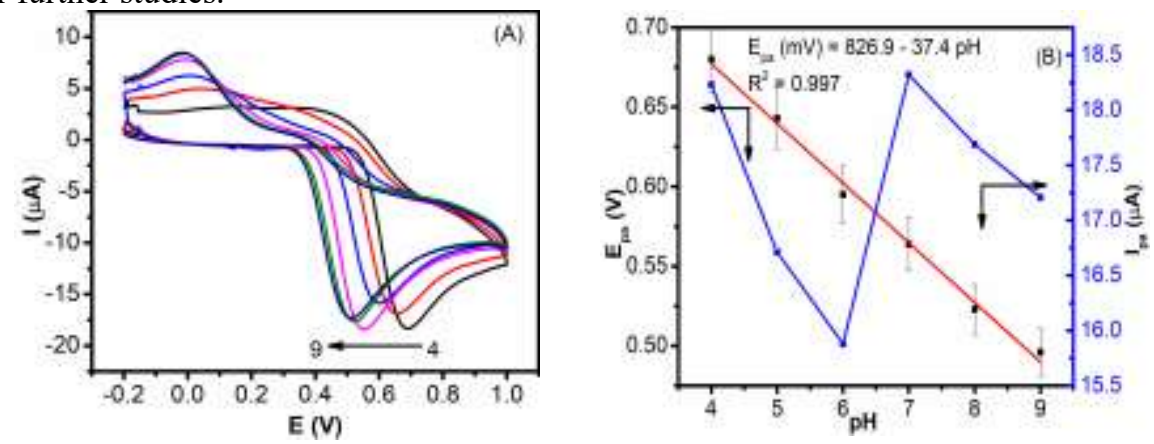

Figure 6. (A) Cyclic voltammograms of MXCPE in PBS of various pHs (4.0, 5.0, 6.0, 7.0, 8.0, 9.0, respectively) containing $0.5 \mathrm{mM} \mathrm{PA}$, and (B) plot of oxidative peak potential (red curve) and peak current (blue curve) as a function of $\mathrm{pH}$ in the entire range (4.0-9.0).

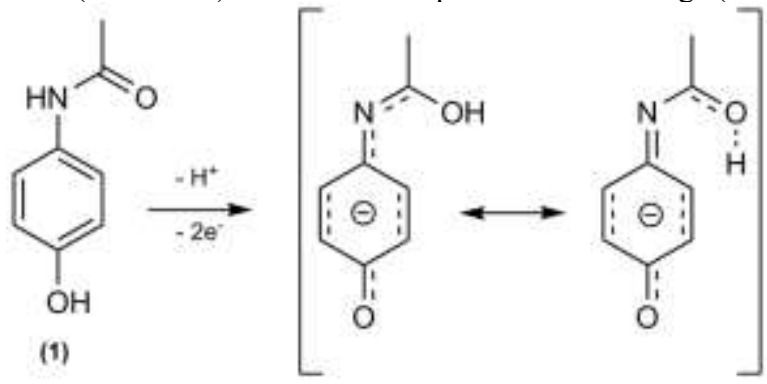

Scheme 3. Electrochemical oxidation of PA (1).

\section{Differential pulse stripping Voltammetric behavior of PA at the MXCPE}

\section{Effect of accumulation potential and time}

Because of the oxidation of PA, the accumulation step could increase to make the peak currents increased. The accumulation potential $\left(\mathrm{E}_{\mathrm{acc}}\right)$ and accumulation time $\left(\mathrm{t}_{\mathrm{acc}}\right)$ with stripping voltammetry technique are shown in Figure 7. 


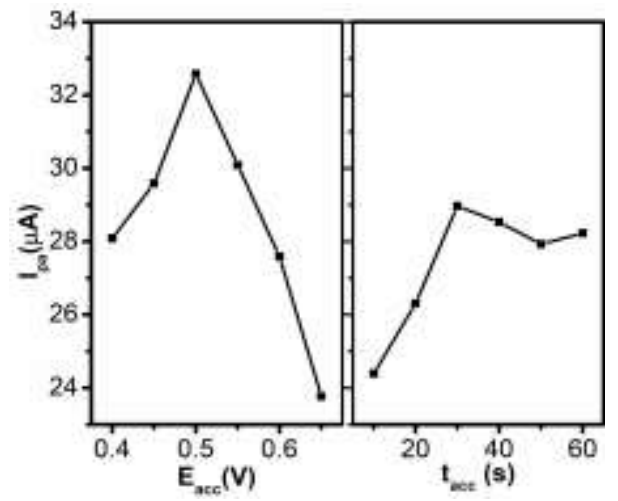

Figure 7. Effect of accumulation potential (left) and accumulation time (right) on peak currents of PA $(0.5 \mathrm{mM})$.

It can be seen from Figure 7 (left panel) that in the accumulation potential range from $0.4 \mathrm{~V}$ to $0.65 \mathrm{~V}$, the peak currents increased between $0.4 \mathrm{~V}$ to $0.5 \mathrm{~V}$, and then decreased to $0.65 \mathrm{~V}$. Thus, $0.5 \mathrm{~V}$ was chosen as optimal accumulation potential for the further voltammetric studies of PA with DPSV. Accumulation time was also tested over the range of 10 to $60 \mathrm{~s}$ (Figure 7, right panel). It is observed that oxidation peak current was increased rapidly and reached maximum at $30 \mathrm{~s}$, then decreased until $60 \mathrm{~s}$ accumulation time. It is suggested that the adsorption quantity of PA on the MXCPE reached saturation. In reflection of both compassion of the examination and working efficiency, $30 \mathrm{~s}$ was nominated as the optimal accumulation time.

\section{Dependence of the oxidative current on the concentration of $P A$}

Under the optimized accumulation potential and time, the made-up MXCPE sensor carried out for the quantitative analysis of PA. Differential pulse stripping voltammetry (DPSV) was applied in this examination because its charging current to the background current is quite low compared to the cyclic voltammetry. Figure 8 shows the dependence of the DPSV oxidation peak current with different concentrations of PA. The relation between the oxidative peak current and concentration of PA ([PA]) showed a linear dependence in the range of 5.0 - 1000 $\mu \mathrm{M}$ with a regression equation of $\mathrm{I}_{\mathrm{pa}}(\mu \mathrm{A})=4.45+0.047[\mathrm{PA}] \mu \mathrm{M}\left(\mathrm{R}^{2}=0.996\right)$.

The limit of detection (LOD) of MXCPE was calculated to be $0.09 \mu \mathrm{M}$ PA according to the equation $3 \mathrm{~S} / \mathrm{M}$, where $\mathrm{M}$ is the slope of the calibration graph and $\mathrm{S}$ is standard deviation of the blank solution $(\mathrm{n}=8)$ (Miller and Miller, 2018). The obtained LOD value is compared with other reported modified electrodes (Table 1). 


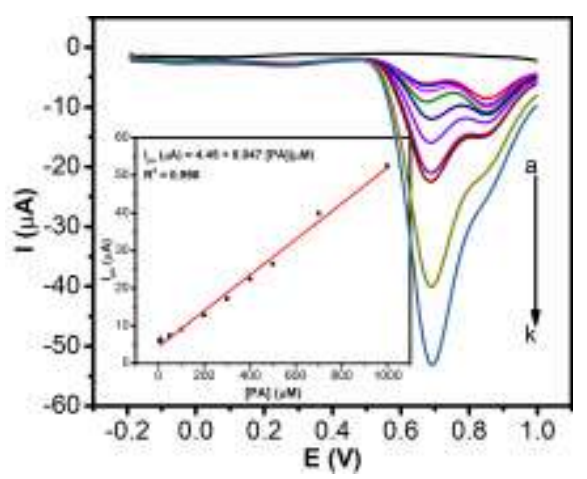

Figure 8. DPSVs of different concentrations $(\mathrm{b} \rightarrow \mathrm{k}): 5,10,50,100,200,300,400,500,700$, and $1000 \mu \mathrm{M}$ PA in PBS pH 7.0 on MXCPE and curve (a) is the blank. Inset: Plot of $\mathrm{I}_{\mathrm{pa}}$ versus concentrations of PA.

Table 1. Comparison of the effectiveness of some modified electrodes for the detection of PA.

\begin{tabular}{llll}
\hline Electrodes & Techniques & $\begin{array}{l}\text { Detection } \\
\text { limit } \\
(\mu \mathbf{M})\end{array}$ & References \\
\hline $\begin{array}{l}\text { Graphene chitosan (GR-CS) } \\
\text { nanocomposite/GCE }\end{array}$ & DPV & 0.3 & (Zheng et al., 2013) \\
$\begin{array}{l}\text { Ethynylferrocene (EF) and } \\
\text { NiO/MWCNT }\end{array}$ & SWV & 0.5 & (Shahmiri et al., 2013) \\
$\begin{array}{l}\text { nanocomposite/CPE } \\
\begin{array}{l}\text { Nanosheet- assembled lindgrenite } \\
\text { microflowers/GCE }\end{array}\end{array}$ & DPV & 0.01 & (Fu et al., 2020) \\
$\begin{array}{l}\text { MWCNTs/ZnO } \\
\text { nanoparticles/GPE }\end{array}$ & DPV & 0.0033 & (Patil et al., 2019) \\
$\begin{array}{l}\text { Phosphorus-doped graphene/GCE } \\
\text { Murexide/CPE }\end{array}$ & DPV & 0.36 & (Zhang et al., 2018) \\
\hline & DPSV & 0.09 & This work \\
\hline
\end{tabular}

\section{Analytical application}

DPSV technique was used to determine PA in three tablet samples. In the study, Panadol Adva (Kenya), Para Denk (Germany), and Julphar Aldol (Ethiopia) brand tablets accessible at local pharmacies were used. The tablet samples were precisely weighed and finely ground in a mortar. A chosen amount of powder (tablet sample) is mixed with a prepared solution of PBS. Afterward, a $20 \mathrm{~mL}$ prepared solution was transferred to the cell and the current response was noticed. As shown in Figure 9, the results confirm the consistent sensitivity of the MXCPE electrochemical response. The results were summarized in Table 2. The calculated relative errors indicated that the accuracy of this analytical method was assessed to be $\leq 5.60 \%$. 


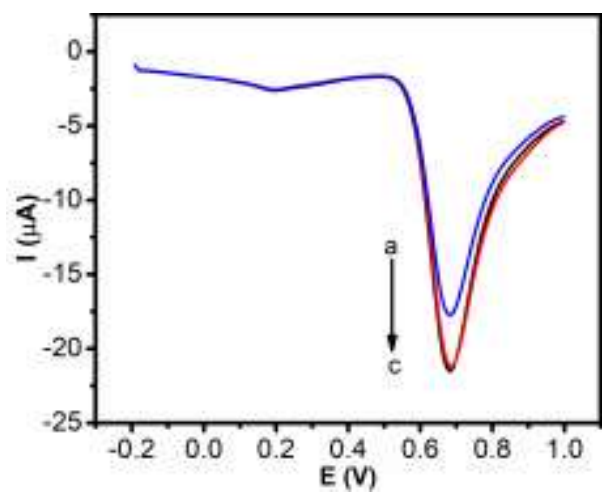

Figure 9. DPSVs of MXCPE in PBS of pH 7.0 containing PA tablet samples of different brands (a $\rightarrow$ c; Kenya, Germany, and Ethiopia).

Table 2. Determination of PA in pharmaceutical tablet samples.

\begin{tabular}{llllllll}
\hline Tablet sample & $\begin{array}{l}\text { Declared } \\
\text { PA } \\
\text { content } \\
\text { (mg/tablet) }\end{array}$ & $\begin{array}{l}\text { Detected } \\
\text { method }\end{array}$ & $\mathbf{\mu A}$ & by this & $\begin{array}{l}\text { PA } \\
\text { found } \\
\text { (\%) }\end{array}$ & $\begin{array}{l}\text { Relative } \\
\text { error } \\
\text { (\%) }\end{array}$ \\
& & & & & \\
\hline Pandol Adva (Kenya) & 500 & 53.69 & 488 & 97.6 & 2.45 \\
Para Denk (Germany) & 500 & 56.0 & 508 & 100.1 & 1.57 \\
Adol Julphar (Ethiopia) & 500 & 58.40 & 530 & 106.0 & 5.60 \\
\hline
\end{tabular}

*Relative error $=100 \% \times($ detected value - declared value $) /$ detected value

The determination of PA on the sensing performance in real pharmaceutical samples using the developed method was investigated by using the standard addition method. The results are listed in Table 3. Upon addition of certain amounts of PA, excellent recovery results (94.6-96.8 \%) are obtained. These results confirm that the MXCPE is a promising electrode material for the sensitive and selective detection of PA in real pharmaceutical tablets.

Table 3. Summary of recovery results of $110.0 \mu \mathrm{M}$ PA from tablet solutions.

\begin{tabular}{llll}
\hline Tablet sample & $\begin{array}{l}\text { Spiked } \\
\text { PA }(\boldsymbol{\mu M})\end{array}$ & $\begin{array}{l}\text { Detected PA } \\
(\boldsymbol{\mu} \mathbf{M})\end{array}$ & $\begin{array}{l}\text { Recovery } \\
(\%)\end{array}$ \\
\hline Julphar aldol (Ethiopia) & 66 & 166.50 & 94.60 \\
Para Denk (Germany) & 66 & 168.43 & 95.69 \\
Panadol Adava (Kenya) & 66 & 170.50 & 96.87 \\
\hline
\end{tabular}

\section{Interference study}

An accuracy of the analysis can be pretentious by the limitation of analytical selectivity. For the proposed method in the determination of PA the selectivity of 
the method was evaluated in the presence of foreign species. For the interference study different amount of ascorbic acid (AA) was used. Under optimized conditions, a comment interferent of $50 \mu \mathrm{M}$ and $100 \mu \mathrm{M}$ AA was added into 100 $\mu \mathrm{M}$ and then the alteration of the peak current was checked. As can be seen from Figure 10, there was no change in the peak current and peak potential occurred for PA. From Table 4, the change in signal indicates almost no influence on the detection of PA, since the peak current varied approximately below 5\% which discloses that the MXCPE sensor has good sensitivity for PA determination.

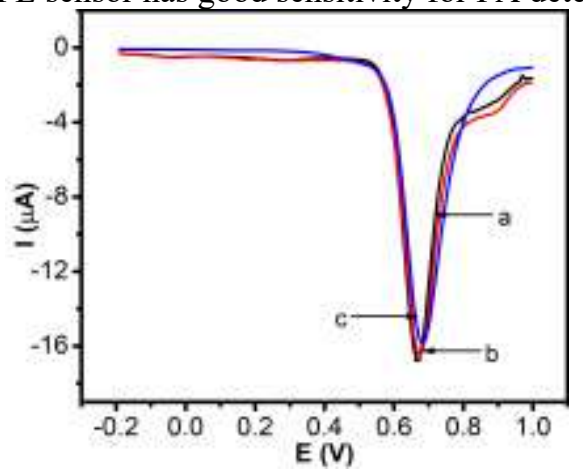

Figure 10. DPSVs in PBS of pH 7.0 containing (a) Ethiopian PA tablet solution, (b) $\mathrm{a}+50 \mu \mathrm{M}$ AA and (c) $\mathrm{a}+100 \mu \mathrm{M}$ AA.

Table 4. Effect of AA interferent on the DPSV response of $50 \mu \mathrm{M}$ PA at MXCPE.

\begin{tabular}{lcccc}
\hline Tablet & PA $(\boldsymbol{\mu M})$ & $\begin{array}{l}\text { Added } \\
\mathbf{A A}(\boldsymbol{\mu M})\end{array}$ & $\begin{array}{l}\text { Recorded } \\
\mathbf{I}_{\mathbf{p a}}(\boldsymbol{\mu A})\end{array}$ & \multicolumn{2}{l}{$\begin{array}{l}\text { \% } \\
\text { Error }\end{array}$} \\
\hline Julphar Aldol & 100 & ------ & 16.86 & $---{ }^{--}$ \\
(Ethiopia) & 100 & 50 & 16.58 & 1.68 \\
& 100 & 100 & 15.88 & 5.81 \\
\hline
\end{tabular}

\section{CONCLUSION}

A modified electrode, MXCPE, was fabricated by modifying the CPE by using murexide and subsequent mixing with graphite and paraffin oil. The MXCPE exhibits an excellent electrocatalytic oxidation activity towards paracetamol. The response for the oxidation of paracetamol at MXCPE shows an improved onset potential shift by $65 \mathrm{mV}$ when equated to CPE. For the experimental conditions, the effect of scan rate, $\mathrm{pH}$, accumulation potentials and time were studied. The scan rate studies indicated that paracetamol undergoes a diffusion process on the modified electrode. Furthermore, the common analytical interfering, ascorbic acid introduced did not affect the peak positions of paracetamol in pharmaceutical samples. 


\section{ACKNOWLEGEMENTS}

The authors would like to gratefully acknowldge Department of Chemistry, Bahir Dar University for providing facilities and Prof. Meareg Amare for his support to conduct and complete the study.

\section{REFERENCES}

Al-Zoubi, N., Koundourellis, J and Malamataris, S. (2002). Ft-ir and raman spectroscopic methods for identification and quantitation of orthorhombic and monoclinic paracetamol in powder mixes. Journal of Pharmaceutical and Biomedical Analysis 29: 459-467: https://doi.org/10.1016/S0731-7085(02)00098-5.

Anderson, B.J. (2008). Paracetamol (acetaminophen): Mechanisms of action. Pediatric Anesthesia 18: 915-921: https://doi.org/10.1111/j.1460-9592.2008.02764.x.

Baptistao, M., Rocha, W.F.D.C and Poppi, R. J. (2011). Quality control of the paracetamol drug by chemometrics and imaging spectroscopy in the near infrared region. Journal of Molecular Structure 1002: 167-171: https://doi.org/10.1016/i.molstruc.2011.07.019.

Bard, A.J and Faulkner, L.R. (2001). Fundamentals and applications. Electrochemical Methods 2: 580-632.

Barsan, M.M., Toledo, C.T and Brett, C.M. (2015). New electrode architectures based on poly (methylene green) and functionalized carbon nanotubes: Characterization and application to detection of acetaminophen and pyridoxine. Journal of Electroanalytical Chemistry 736: 8-15: https://doi.org/10.1016/j.jelechem.2014.10.026.

Bertolini, A., Ferrari, A., Ottani, A., Guerzoni, S., Tacchi, R and Leone, S. (2006). Paracetamol: New vistas of an old drug. CNS Drug Reviews 12: 250-275: https://doi.org/10.1111/j.1527-3458.2006.00250.x.

Bharathi, K., Kumar, S.P., Prasad, P.S and Narayanan, V. (2018). Voltammertic determination of paracetamol by $\mathrm{n}$, n'-bis (salicylaldimine)-benzene-1, 2-diamine chromium (iii) schiff base complex modified gce. Materials Today: Proceedings 5: 8961-8967: https://doi.org/10.1016/j.matpr.2017.12.336.

Bouabi, Y.E., Farahi, A., Achak, M., Zeroual, M., Hnini, K., El Houssame, S., Bakasse, M., Bouzidi, A and El Mhammedi, M. (2016). Electrocatalytic effect of fluoroapatite in reducing paracetamol at carbon paste electrode: Analytical application. Journal of the Taiwan Institute of Chemical Engineers 66: 33-42: https://doi.org/10.1016/j.jtice.2016.06.013.

Chipeture, A.T., Apath, D., Moyo, M and Shumba, M. (2019). Multiwalled carbon nanotubes decorated with bismuth (iii) oxide for electrochemical detection of an antipyretic and analgesic drug paracetamol in biological samples. Journal of Analytical Science and Technology 10: 22: https://10.0.4.162/s40543-019-0181-5.

Filik, H., Avan, A.A., Aydar, S and Çetintaş, G. (2014). Determination of acetaminophen in the presence of ascorbic acid using a glassy carbon electrode modified with poly (caffeic acid). International Journal of Electrochemical Science 9: 148-160: http://citeseerx.ist.psu.edu/viewdoc/download?doi=10.1.1.661.1673.

Foroughi, M.M., Jahani, S and Hassani Nadiki, H. (2019). Lanthanum doped fern-like cuo nanoleaves/mwcnts modified glassy carbon electrode for simultaneous determination of 
tramadol and acetaminophen. Sensors and Actuators B: Chemical 285: 562-570: https://doi.org/10.1016/j.snb.2019.01.069.

Fu, R., Shen, M., Ding, Y., Li, M., Li, L., Ren, Z and Wu, Q. (2020). Electrocatalytic oxidation and sensitive determination of paracetamol based on nanosheets self-assembled lindgrenite microflowers. Electroanalysis 32: 978-985: https://doi.org/10.1002/elan.201900504.

Ghadimi, H., Tehrani, R.M., Basirun, W.J., Ab Aziz, N.J., Mohamed, N and Ab Ghani, S. (2016). Electrochemical determination of aspirin and caffeine at mwcnts-poly-4vinylpyridine composite modified electrode. Journal of the Taiwan Institute of Chemical Engineers 65: 101-109: https://doi.org/10.1016/j.jtice.2016.05.043.

Görçay, H., Çelik, İ., Yurdakul, E., Şahin, Y and Kökten, Ş. (2016). Highly sensitive electrochemical determination of acetaminophen in pharmaceuticals by poly [2, 5-di (2thiophenyl)-1-p-(tolyl) pyrrole] modified pencil graphite electrode. IEEE Sensors Journal 16: 2914-2921: https://doi.org/10.1109/JSEN.2016.2526609.

Gowda, J.I., Gunjiganvi, D.G., Sunagar, N.B., Bhat, M.N and Nandibewoor, S. T. (2015). Mwcnt-ctab modified glassy carbon electrode as a sensor for the determination of paracetamol. RSC Advances 5: 49045-49053: https://doi.org/10.1039/C5RA05802C.

Goyal, A and Jain, S. (2007). Simultaneous estimation of paracetamol, chlorzoxazone and diclofenac sodium in pharmaceutical formulation by a novel hplc method. Acta $\begin{array}{lll}\text { Pharmaceutica Sciencia 147-151: } & \text { 49: }\end{array}$ http://www.actapharmsci.com/uploads/pdf/pdf 112.pdf.

Khaskheli, A.R., Fischer, J., Barek, J., Vyskočil, V., Sirajuddin, S. and Bhanger, M.I. (2013). Differential pulse voltammetric determination of paracetamol in tablet and urine samples at a micro-crystalline natural graphite-polystyrene composite film modified electrode. Electrochimica Acta 101: 238-242: https://doi.org/10.1016/i.electacta.2012.09.102.

Kissinger, P.T and Heineman, W.R. (1983). Cyclic voltammetry. Journal of Chemical Education 60: 702-706: https://pubs.acs.org/doi/abs/10.1021/ed060p702.

Laviron, E. (1979). General expression of the linear potential sweep voltammogram in the case of diffusionless electrochemical systems. Journal of Electroanalytical Chemistry and Interfacial Electrochemistry 101: 19-28: https://doi.org/10.1016/S00220728(79)80075-3.

Lecoeur, M., Rabenirina, G., Schifano, N., Odou, P., Ethgen, S., Lebuffe, G and Foulon, C. (2019). Determination of acetaminophen and its main metabolites in urine by capillary electrophoresis hyphenated to mass spectrometry. Talanta 205: 120108: https://doi.org/10.1016/j.talanta.2019.07.003.

Li, C., Xu, J., Wu, Y., Zhang, Y., Zhang, C., Lei, W and Hao, Q. (2018). G-c3n4 nanofibers doped poly(3,4-ethylenedioxythiophene) modified electrode for simultaneous determination of ascorbic acid and acetaminophen. Journal of Electroanalytical Chemistry 824: 52-59: https://doi.org/10.1016/j.jelechem.2018.07.025.

Meenakshi, S., Pandian, K and Gopinath, S.C.B. (2020). Quantitative simultaneous determination of pentoxifylline and paracetamol in drug and biological samples at graphene nanoflakes modified electrode. Journal of the Taiwan Institute of Chemical Engineers 107: 15-23: https://doi.org/10.1016/i.jtice.2019.11.011.

Miller, J and Miller, J.C. (2018). Statistics and chemometrics for analytical chemistry, Pearson education.

Mohran, H.S. (2009). An electrochemical investigation of the redox properties of murexide in aqueous and non-aqueous media. American Journal of Applied Sciences 6: 964-969: https://doi.org/10.3844/ajassp.2009.964.969. 
Moreira, A.B., Oliveira, H.P., Atvars, T.D., Dias, I.L., Neto, G.O., Zagatto, E. A and Kubota, L.T. (2005). Direct determination of paracetamol in powdered pharmaceutical samples by fluorescence spectroscopy. Analytica Chimica Acta 539: 257-261: https://doi.org/10.1016/j.aca.2005.03.012.

Patil, D.S., Shetti, N.P., Nayak, D.S and Revankar, R.S. (2019). Fabrication of multi-walled carbon nanotubes and zno nanoparticles composite electrode as a sensor for paracetamol. Materials $\quad$ Today: $\quad$ Proceedings 18: 1124-1131: https://doi.org/10.1016/j.matpr.2019.06.572.

Shah, A.H., Shah, A., Rana, U.A., Khan, S.U.D., Hussain, H., Khan, S.B., Qureshi, R and Badshah, A. (2014). Redox mechanism and evaluation of kinetic and thermodynamic parameters of 1,3-dioxolo [4, 5-g] pyrido [2, 3-b] quinoxaline using electrochemical techniques. Electroanalysis 26: 2292-2300: https://doi.org/10.1002/elan.201400324.

Shahmiri, M.R., Bahari, A., Karimi-Maleh, H., Hosseinzadeh, R and Mirnia, N. (2013). Ethynylferrocene-nio/mwcnt nanocomposite modified carbon paste electrode as a novel voltammetric sensor for simultaneous determination of glutathione and acetaminophen. Sensors and Actuators B: Chemical 177: 70-77: https://doi.org/10.1016/j.snb.2012.10.098.

Shinde, V., Desai, B and Tendolkar, N. (1995). Simultaneous determination of paracetamol, diclofenac sodium and chlorzoxazone by hplc from tablet. Indian Journal of Pharmaceutical Sciences 57: 35-37.

Zhang, X., Wang, K.-P., Zhang, L.-N., Zhang, Y.-C and Shen, L. (2018). Phosphorus-doped graphene-based electrochemical sensor for sensitive detection of acetaminophen. Analytica Chimica Acta 1036: 26-32: https://doi.org/10.1016/j.aca.2018.06.079.

Zheng, M., Gao, F., Wang, Q., Cai, X., Jiang, S., Huang, L and Gao, F. (2013). Electrocatalytical oxidation and sensitive determination of acetaminophen on glassy carbon electrode modified with graphene-chitosan composite. Materials Science and Engineering: C 33: 1514-1520: https://doi.org/10.1016/j.msec.2012.12.055.

Zhu, W., Huang, H., Gao, X and Ma, H. (2014). Electrochemical behavior and voltammetric determination of acetaminophen based on glassy carbon electrodes modified with poly (4-aminobenzoic acid)/electrochemically reduced graphene oxide composite films. Materials Science and Engineering: $C$ 45: 21-28: https://doi.org/10.1016/j.msec.2014.08.067. 